\title{
O USO de DADOS PESSOAIS E A ATUAÇÃO DE PODERES PRIVAdOS COMO SINTOMAS DE UM ESTADO EM CRISE: REFLEXÕES SOBRE OS RISCOS AOS PROCESSOS DEMOCRÁTICOS NACIONAIS
}

\section{THE USE OF PERSONAL DATA AND THE ACTING OF PRIVATE POWERS AS SYMPTOMS OF A STATE IN CRISIS: REFLECTIONS ABOUT THE RISKS TO NATIONAL DEMOCRATIC PROCESSES}

\author{
Tássia A. Gervasoni ${ }^{1}$ \\ Rafaela Rovani de Linhares ${ }^{2}$
}

\section{RESUMO}

O artigo aborda discussões acerca dos riscos do uso de dados pessoais nos processos democráticos, no contexto da crescente atuação de poderes privados e da crise do Estado. O intuito da pesquisa é responder ao problema: considerando um cenário de globalização e de crise do Estado, quais são os impactos decorrentes da utilização de dados pessoais sobre os processos democráticos e qual seria a relevância de um direito fundamental à proteção de dados pessoais no ordenamento constitucional brasileiro? A hipótese de pesquisa sugere que o avanço da atuação de poderes privados nos processos decisórios e de regulamentação torna a autoridade do Estado fragilizada e incapaz de dar respostas adequadas às demandas do atual mundo globalizado. Nesse caso, nota-se especial dificuldade dos Estados em regular as matérias atinentes a dados pessoais, pelo fato de a regulação de questões tecnológicas ter caráter eminentemente privado e, além disso, tratar de matérias para além das fronteiras de um único Estado. A dificuldade de regulação implica na própria ausência de controle de empresas que atuam manipulando, vendendo e comprando dados pessoais de milhões de usuários no mundo todo. $\mathrm{O}$ marco teórico de referência para a análise proposta é o constitucionalismo garantista. A pesquisa desenvolveu-se a partir do por meio do método dedutivo e da técnica de pesquisa bibliográfica.

Palavras-chave: dados pessoais; poderes privados; crises do Estado; democracia; direito fundamental.

\begin{abstract}
The article addresses discussions about the risks of using personal data in democratic processes, in the context of the growing acting of private powers and the crisis of the State. The aim of the research is to answer the problem: considering a scenario of globalization and the crisis of the State, what are the impacts resulting from the use of personal data on democratic processes and what

\footnotetext{
${ }^{1}$ Doutora em Direito pela Universidade do Vale do Rio dos Sinos, com período sanduíche na Universidad de Sevilla (Espanha). Mestre e Graduada em Direito pela Universidade de Santa Cruz do Sul. Professora de Direito Constitucional e Ciência Política na Faculdade Meridional - IMED/Passo Fundo. Professora do Programa de PósGraduação Stricto Sensu - Mestrado na Faculdade Meridional - IMED/Passo Fundo. Pesquisadora do Grupo de Pesquisa Estado e Constituição, vinculado ao CNPq. Lattes: http://lattes.cnpq.br/2356663578448676. ORCID: http://orcid.org/0000-0002-8774-5421. E-mail: tassiagervasoni@gmail.com

${ }^{2}$ Mestranda em Direito na Faculdade Meridional - IMED/Passo Fundo. Bolsista CAPES. Graduada em Direito pela Faculdade Meridional - IMED. Lattes:http://lattes.cnpq.br/5013146083316542. ORCID: http://orcid.org/0000-0003-4331-8062 E-mail: rafaelarovani@hotmail.com
} 
would be the relevance of a fundamental right to the protection of personal data in the Brazilian constitutional order? The research hypothesis suggests that the advancement of the role of private powers in decision-making and regulation processes makes state authority weak and unable to provide adequate responses to the demands of the current globalized world. In this case, there is a special difficulty for States to regulate matters relating to personal data, since the regulation of technological issues is eminently private and, in addition, dealing with matters beyond the borders of a single State. The difficulty of regulation implies the lack of control of companies that manipulate, sell and buy personal data of millions of users worldwide. The theoretical framework of reference for the proposed analysis is the guarantor constitutionalism. The research was developed through the deductive method and the bibliographic research technique.

Keywords: personal data; private powers; state crises; democracy; fundamental right.

\section{INTRODUÇÃO}

Há muito se discute acerca de temas desafiadores das engrenagens institucionais do Estado que, com bases modernas, encontra dificuldades para contornar as questões atuais de uma sociedade amplamente globalizada. No caso dos avanços tecnológicos, não é diferente, já que os Estados se confrontam com realidades que, mais do que nunca, ultrapassam suas fronteiras. De modo especial, o tema da utilização dos dados pessoais tem relação direta com os processos democráticos no interior dos Estados e, ao lado da crescente atuação de poderes privados nesses domínios, torna-se uma discussão de especial relevância.

Com base nesses elementos, a pesquisa pretende responder ao seguinte problema: considerando um cenário de globalização e de crise do Estado, quais são os impactos decorrentes da utilização de dados pessoais sobre os processos democráticos e qual seria a relevância de um direito fundamental à proteção de dados pessoais no ordenamento constitucional brasileiro?

A hipótese de pesquisa sugere que, por meio da globalização, do avanço de novas tecnologias e do amplo acesso das pessoas à rede, é possível estabelecerem-se conformações de crises dos Estados, principalmente pelo avanço da atuação de poderes privados nos processos decisórios e de regulamentação, tornando a autoridade do Estado fragilizada e incapaz de dar respostas adequadas às demandas do atual mundo globalizado. Nesse caso, nota-se especial dificuldade dos Estados em regular as matérias atinentes a dados pessoais, pelo fato de a regulação de questões tecnológicas ter caráter eminentemente privado e, além disso, tratar de matérias para além das fronteiras de um único Estado. A dificuldade de regulação implica na própria ausência de controle de empresas que atuam manipulando, vendendo e comprando dados pessoais de milhões de usuários no mundo todo. 
Essas imbricações implicam efeitos imediatos nas democracias dos Estados, desde a manipulação de eleições, até determinação de políticas públicas. No Brasil, muito se discute acerca da necessidade de incluir a proteção de dados pessoais no catálogo de direitos fundamentais. Contudo, entende-se que, diante da atuação de poderes privados nas mais diversas localidades do mundo, tal direito pode revestir-se baixa efetividade, tendo em vista que a manipulação de dados pessoais ultrapassa fronteiras e, por isso, não se vincula necessariamente à jurisdição de um Estado específico.

O objetivo geral do trabalho é analisar, considerando um cenário de globalização e crise do Estado, os impactos decorrentes da utilização de dados pessoais sobre os processos democráticas e qual a relevância de um direito fundamental à proteção de dados pessoais no ordenamento constitucional brasileiro. Os objetivos específicos são: (a) contextualizar as crises do Estado, bem como o avanço da globalização e das questões tecnológicas para além das fronteiras; (b) conceituar elementos acerca de dados pessoais, sua utilização e instrumentos legais existentes no Brasil; (c) avaliar a correlação entre a utilização de dados pessoais os processos democráticos e, a partir disso, a função e relevância de um direito fundamental à proteção de dados pessoais no ordenamento jurídico brasileiro.

O trabalho será desenvolvido a partir do marco teórico do constitucionalismo garantista, notadamente no sentido ferrajoliano, vinculado a uma concepção substancial de democracia. A abordagem ser dará por meio do método dedutivo, pois partirá da análise de categorias gerais para, no decorrer da pesquisa e aprofundamento do estudo dessas categorias, especificá-las e inseri-las em perspectivas mais concretas. Como método de procedimento, adotar-se-á o método monográfico, tendo em vista um recorte de tema rigorosamente delimitado desde o início. Por fim, a técnica de pesquisa será a documentação indireta, por meio da pesquisa bibliográfica.

\section{CRISE, GLOBALIZAÇÃO E O "FIM DA GEOGRAFIA" DO ESTADO}

Pode-se dizer que os processos que se convencionou chamar de crises do Estado dizem respeito a um confrontamento existente na sua estrutura por questões que afetam diretamente a fórmula estatal da modernidade. Para fazer uso da expressão de Bolzan de Morais (2018, p. 17), essas crises representam o "fim da geografia institucional do Estado", alicerçada, principalmente, sobre os pilares povo, soberania e base territorial definida por um espaço delimitado.

Inobstante às inflexões ocorridas em âmbito do funcionamento das instituições estatais e que desafiam sua engrenagem institucional, deve ser destacado o modo como a globalização 
contribui para esses confrontamentos. Com efeito, a globalização, ao permitir a circulação de bens, pessoas, mercadorias e capitais, dentre outros, criou um território mundial, divergente da antiga fórmula territorial moderna. Por isso, o cenário que pretende se evidenciar nesse ponto do trabalho permite associar as relações contemporâneas entre globalização e crises do Estado.

A globalização, por sua multiplicidade de sentidos, não pode ser traduzida a um único conceito, todavia, aproveitando-se da lição de Beck, compreende-se que com a globalização "vaise derrubando passo a passo umas das principais premissas da primeira modernidade, a saber: $a$ ideia de que se vive e se interage nos espaços fechados e mutuamente delimitados dos Estados nacionais". Conforme definição do autor, "a globalização significa a experiência cotidiana da ação sem fronteiras nas dimensões da economia, da informação, da ecologia, da técnica, dos conflitos transculturais e da sociedade civil [...]" (1999, p. 46).

Reforçando essa percepção, Campuzano discorre acerca das alterações provocadas pela globalização em âmbito econômico, indicando a existência de um conjunto de reações que vão desde a diminuição da capacidade de regulamentação dos governos, até a aparição de novas configurações geopolíticas com poder para controlar os fluxos produtivos, mercantis, monetários e migratórios. Nesse sentido, a globalização, além de superar as economias parciais dos Estados, inaugurou um espaço global implicando, fundamentalmente, um salto qualitativo na expansão do capitalismo, desvinculado do modelo econômico estatal e, por isso, "apátrida, sem raízes e sem território", buscando o máximo benefício (2003, p. 20-21).

Parte-se da premissa de que Estado, soberania, território e povo são conceitos edificados durante a modernidade que e permitiram a construção dos ordenamentos jurídicos nacionais. Porém, estes conceitos estão sendo desafiados pela realidade, e já parece não serem mais aplicáveis a uma dimensão mundial dominada pela transnacionalização da economia, pelas mudanças introduzidas continuamente pela inovação científica e tecnológica, por uma rede eletrônica que envolve o mundo e apaga as fronteiras (RODOTÀ, 2003, p. 3).

Nesse sentido, retornando ao termo utilizado no início do texto, é interessante notar que o "fim da geografia do Estado" é propiciado por uma rede de interconexões impulsionadas pela globalização modificando as antigas fronteiras territórios e tornando-as porosas. A nova rede de comunicações e tecnologias provoca, constantemente, uma redução espacial do mundo, abraçando o planeta de um extremo ao outro, provocando a sensação de que as fronteiras são diluídas. Ao passo em que os limites são dispersados, o capitalismo se expande em um ritmo acelerado, gerando fluxos financeiros que escapam a qualquer controle. Significa afirmar, sinteticamente, a perda dos Estados em relação à capacidade de direção, regulação e controle sobre os processos socioeconômicos (CAMPUZANO, 2003, p. 23). 
Ao descrever o avanço dos processos globalizatórios, facilmente se percebe sua intrínseca relação com o enfraquecimento da arquitetura institucional do Estado, fazendo aparecer um aspecto de crise que diz respeito diretamente a sua soberania ${ }^{3}$. Aliás, seguindo na esteira de Chevallier, para quem a globalização exerce "um efeito dissolutivo sobre a soberania estatal", há três maneiras dos Estados serem impactados em sua soberania: primeiro, pela redução de sua margem de liberdade, sendo curvados às exigências de uma ordem transnacional que os ultrapassa; em seguida, pelo fim de seu monopólio tradicional nas relações internacionais, favorecendo o aumento do poderio de novos atores; enfim, sofrendo imposições quanto à constituição de entidades mais amplas, fazendo romper a exiguidade do quadro Estado-nação (2009, p. 38).

De fato, a globalização supõe a expansão e intensificação das relações econômicas, políticas, sociais e culturais para além das fronteiras. De certa forma, há uma economia de âmbito global, presumindo a interação entre seus processos e as políticas adotadas pelas instituições estatais, o que denota que tanto os Estados, como os demais atores nesses cenários não são meros objetos passivos e sim peças determinantes do avanço da globalização, seu alcance e direção ${ }^{4}$.

Contudo, ao refletir o modo como a economia nacional do Estado moderno se transforma, deve-se levar em conta que a extensão da globalização não ocorre de maneira uniforme entre os países. Com efeito, as corporações transnacionais organizam cadeias de produção de caráter regional ou global, contando com medidas políticas de liberalização do intercâmbio econômico entre países. Sem dúvidas quanto à inexistência de uma economia global unificada, homogênea e integrada, Sørensen afirma que se trata de um processo de desenvolvimento desigual em que algumas economias nacionais (especialmente Europa Ocidental, América do Norte e Ásia Oriental) participam de um modo mais ativo que outras economias menos desenvolvidas do terceiro mundo que tendem, inclusive, a serem marginalizadas nesse contexto (2010, p. 44-52).

\footnotetext{
${ }^{3}$ Consoante lição de Bolzan de Morais, a crise conceitual atinge o Estado em sua principal característica: o poder, como soberania. O sentido que se atribui a essa crise tem correspondência com a imbricação dos poderes na atual ordem globalizada que implica uma revisão em muitos dos postulados da soberania, favorecendo uma revisão do seu conceito mais tradicional como poder superior. Para o autor, nos movimentos da sociedade global, há um processo de redefinição da soberania do Estado que é comprometida pela fragilidade de sua autoridade, ao passo em que o exaurimento do equilíbrio dos poderes e a perda de autonomia decisória estatal são revelados conforme se posicionam os mais distintos setores econômicos, interferindo em realidades que, até pouco tempo, dependiam tão somente do aparato institucional do Estado (2011, p. 27).

${ }^{4}$ A perspectiva de Sassen para a compreensão de um novo contexto de funcionamento do Estado é muito relevante nesse sentido. O ponto de vista da autora indica que a ordem institucional privada que está em formação é marcada pela capacidade de privatizar o que até então era público e desnacionalizar os programas políticos nacionais. A ascensão da autoridade privada, desempenhando um papel central num campo em que também operam os Estados, indica a privatização de domínios antes exclusivos do Estado. Contudo, deve-se destacar que tanto a capacidade de privatizar, quanto a desnacionalização são fatores intrínsecos do Estado. Por isso, “[...] a ascensão da autoridade privada não é simplesmente uma força externa que restringe o Estado, mas que também é, em parte, um fator endógeno". É importante reconhecer que as instituições estatais são reorientadas em favor das exigências de uma nova ordem normativa orientada pela economia global (2010, p. 222-223).
} 
Não se trata de negar a existência da soberania dos países, mas de reconhecer que, da forma como concebida durante a modernidade, não encontra correspondência com a realidade da atual ordem global. Sobretudo, deve-se ter a compreensão de que embora ela exista, é ineficiente ou incapaz de sustentar o atual funcionamento do Estado, pela presença de poderes privados atuando e regulando esferas que fogem de seu controle de atuação. $\mathrm{O}$ que de fato a pesquisa procura evidenciar é que, com a crescente interdependência, se produz uma distribuição de poderes determinada pelas relações políticas e econômicas que traz consequências graves para as pessoas e para os Estados, em termos de domínio e assimetria de poderes.

Possivelmente nunca se tenha notado tanto a insuficiência dos modelos institucionais de organização inaugurados pela modernidade, como nas crises em que o Estado tem enfrentado nos últimos anos. Há uma esfera de atuação na qual agem diversos sujeitos, "cada um recortando uma parte do poder antes unificado nas mãos do sujeito nacional e, ao contrário do que acontecia (e em parte ainda acontece) nos Estados Nacionais". A atuação desses poderes fora de qualquer controle e visibilidade, fechado em oligarquias políticas ${ }^{5}$ e econômicas cada vez mais restritas, contradizem o fundamento da democracia como "governo do povo" (RODOTÀ, 2003, p. 8).

Há uma série de imbricações que podem ser traçadas acerca da relação entre as crises do Estado e a democracia ${ }^{6}$. Um dos pontos assinalados por Ferrajoli, no tocante ao esvaziamento das formas representativas da democracia, diz respeito à perda de atuação dos governos democraticamente eleitos em função dos interesses públicos gerais que, na verdade, passaram a ser controlados por potências invisíveis e politicamente irresponsáveis do capital financeiro. Dessa forma, os poderes privados globais operam um sistema no qual não há limites, nem vínculos legais e institucionais (como é o caso do Estado), enfraquecendo o nexo entre democracia, povo e poderes decisórios (2015, p. 150).

Como o objetivo do texto, mais adiante, será correlacionar a ausência de controle do Estado em relação aos poderes privados - já como diagnóstico dessas crises que abalam os elementos constitutivos do Estado (povo, território e soberania) -, com a proteção de dados pessoais, será

\footnotetext{
${ }^{5}$ Após a Segunda Guerra Mundial, o termo a oligarquia passou a ser estudado indicando uma ideia oposta à democracia. A partir daí, sistemas oligárquicos e sistemas democráticos são antagônicos. Nesse contexto, as oligarquias se caracterizam pela presença de um grupo de poder restrito, homogêneo e estável, com uma boa organização interna, governando de modo autoritário, robustecendo o executivo, controlando o judiciário, marginalizando ou excluindo o poder legislativo e desencorajando ou eliminando a oposição (BOBBIO; MATTEUCCI; PASQUINO, 1998, p. 857).

${ }^{6}$ Em certa medida, o exaurimento do equilíbrio dos poderes e a perda de autonomia decisória estatal são revelados conforme se posicionam os mais distintos setores econômicos, ao interferirem em realidades que, até pouco tempo, dependiam tão somente do aparato institucional do Estado. Nesse viés, pode-se afirmar a existência de uma exaustão paradigmática, resultante, dentre outros fatores, dessa imbricação entre a globalização e perda da centralidade do Estado "como unidade privilegiada e exclusiva de gestão econômica, direção política, controle social e iniciativa legislativa" (FARIA, 2004, p. 39).
} 
importante compreender nesse momento como a "sociedade em rede" avança por meio da globalização, fazendo com que muros e fronteiras desapareçam ${ }^{7}$.

Sendo assim, a primeira constatação que se faz é no sentido de que as questões tecnológicas são colocadas para além das fronteiras. Não por acaso, Sassen tenha proposto a noção de território na atualidade desatrelada aos moldes da Paz de Vestflália (regida por fronteiras físicas). Consoante lição da autora, há um processo de realocação dos marcos fronteiriços, na medida em que defende que as fronteiras se localizam no interior das empresas, cidades globais ou organizações transnacionais $(2015$, p. 519-520).

Há ainda que se considerar que os novos centros de poder e controle de informações e dados, certamente, não estão compreendidos dentro da estrutura do Estado-nação. E, pela ausência de mecanismos de regulação, prevalecem as lógicas de mercado impondo regras, visto que a maioria das atividades on-line são de tipo comercial e que a web é considerada como uma gigantesca mina de dados pessoais. O deslocamento do eixo do Estado, como fonte exclusiva de produção normativa, fez com que diversos poderes privados criassem suas normas de auto regulação. Em muitas situações, o contexto é o de uma realidade na qual a comunidade dos negócios está produzindo um direito comum (ou lex mercatória), encomendado a profissionais da técnica jurídica, com redução da própria regra jurídica a uma das muitas mercadorias que podem ser adquiridas no mercado. Tal forma de produção normativa indica como "os grandes interesses econômicos não procuram mais a mediação das instituições políticas, mas agem em tomada direta, também no campo da produção das regras" (RODOTÀ, 2003, p. 8).

A escalada da sociedade em rede afeta todos os estilos de vida, desde os mais íntimos espaços sensoriais ou de lazer para as vidas profissionais, incluindo a política, onde transforma a democracia, revolucionando o voto como um mecanismo de controle da representação pública. Como exemplo, pode ser indicada a expansão da participação popular por meio de redes sociais, dando um novo rosto à democracia. Esse cenário decorre da instantaneidade do fluxo de informações, a supressão de barreiras físicas, e do senso de cooperação direta com representantes políticos (LÔBO; BOLZAN DE MORAIS, 2019, p. 4).

Aliás, nunca é demais esclarecer a existência de uma vinculação entre o Estado de Direito e a democracia. No momento em que o Estado perde sua margem de atuação diante do protagonismo de poderes privados, deixa de honrar seus compromissos com a democracia, caracterizando a erosão não somente de seu plano substancial, pela supressão dos direitos fundamentais, como também do

\footnotetext{
${ }^{7} \mathrm{O}$ componente território, tão importante durante o período moderno, responsável por demarcar limites territoriais sobre os quais o Estado exercia o poder em caráter soberano é apagado por problemas transfronteiriços cada vez mais graves. Muito se discute acerca de questões ambientais, sanitárias, nucleares, econômicas, dentre tantas outras que transcendem as fronteiras geográficas dos Estados (GERVASONI, 2017, p. 232).
} 
plano formal, já que os mecanismos de acesso formal aos processos de tomada de decisão acabam distorcidos $^{8}$ (FERRAJOLI, 2015, p. 37-48).

Se, outrora, o Estado (Democrático) de Direito foi pensado para salvaguardar os direitos fundamentais dos cidadãos, atualmente o cenário de desfragmentação das instituições estatais aponta uma perspectiva diversa, de modo que, ao lado da insuficiência de atuação para a garantia desses direitos, existe um déficit de confiança nas instituições políticas. O poder das grandes corporações empresariais monopoliza as pautas governamentais, fazendo com que a ausência de instrumentos de controle conduza ao enfraquecimento da democracia.

A partir da ruptura com os antigos arranjos de produção, em função de novas formas de desenvolvimento de atividades, algumas polêmicas regulatórias acerca da Internet podem ser verificadas no mundo todo e atestam o desafio que as inovações tecnológicas impõem às instituições estatais. Em cenários caracterizados por uma grande importância material da tecnologia digital e, por isso, mais sujeitos à sua rápida evolução (como telecomunicações e sistema financeiro, por exemplo) a conformação institucional dessas novas formas de produção e desenvolvimento apresenta um desafio ainda maior para o Direito. De todo modo, "quando um determinado arranjo institucional é confrontado com uma nova lógica de organização, uma série de questões passa a incomodar os agentes do Estado, como adequação, momento e forma de regulação do novo contexto" (BAPTISTA; KELLER, 2016, p. 132).

Enfim, as sociedades contemporâneas hiperconectadas desencadeiam a desestabilização das tradicionais estruturas estatais, uma vez que o "poder acaba sendo dispersado em uma rede extremamente flexível e em constante modificação". Por esse e outros motivos, é possível se falar que a revolução da internet ou a sociedade em rede simplesmente ignora as tradicionais fronteiras do Estado-nação, uma vez que a "localização de uma informação armazenada não necessariamente corresponde ao local de violação de um direito fundamental ou ao lugar de sede da empresa que guarda esses dados" (BOLZAN DE MORAIS, 2018, p. 29). De qualquer forma, o cenário fragmentado de atuação dos Estados em relação aos poderes privados impulsionados pela globalização evidencia não somente as crises a que foi submetido, como também o quanto isso compromete/impacta a democracia dos países.

\footnotetext{
${ }^{8}$ Vale destacar que a democracia, enquanto dimensão formal, tem seu fundamento axiológico na representação de todos os governados, por meio da igualdade política e, ao garantir a forma democrática de escolha dos governantes, faz correspondência com a participação política de todos os membros da sociedade na tomada de decisões. Em seu aspecto substancial, ela é fundada na atuação das normas constitucionais substanciais e diz respeito aos limites e vínculos impostos aos poderes (públicos ou privados) voltados à garantia dos direitos fundamentais constitucionalmente assegurados (FERRAJOLI, 2015, p. 37-48).
} 


\section{TECNOLOGIA, DADOS PESSOAIS E OS INSTRUMENTOS LEGAIS EXISTENTES NO BRASIL}

Com a globalização e a evolução das tecnologias e dos recursos vinculados à rede mundial de computadores, a velocidade com que a World Wide Web (Internet) foi popularizada permitiu seu acesso a um número significativo de pessoas no mundo. Por isso, de certa forma, pode-se destacar que esses processos permitiram a disseminação de culturas, acesso e democratização da informação, inclusão digital, dentre outras inovações que propiciaram algumas facilidades decorrentes do uso dessa tecnologia ${ }^{9}$. Contudo, do ponto de vista crítico, devem ser feitas algumas análises acerca de problemas jurídicos advindos da crescente massificação do uso da Internet.

Há uma reflexão crítica muito interessante a se considerar, por exemplo, ao se analisar a forma como o capitalismo digital faz com que as pessoas espontaneamente produzam valor para o capital, gerando uma espécie de "capitalismo cognitivo" (CHIGNOLA, 2015, p. 14). O sujeito incluído no universo digital realiza a inserção de elementos de sua vida em redes sociais ou portais de compartilhamento como Youtube ou Facebook, sem se dar conta de que o seu exercício de liberdade é o que produz conteúdo para as mídias digitais. O fornecimento de "dados pessoais", na maioria das vezes, é feito de forma voluntária pelos usuários da Web: ao trocar e-mails, criar contas em redes sociais, usar aplicativos, fazer compras, testes, jogos, dentre outras atividades, gerando uma imensa quantidade armazenamento de informações sobre os usuários.

Nesse sentido, têm-se observado diversos estudos acerca da manipulação dos dados pessoais dos usuários da Internet. Existe uma série de problemas relacionados à utilização desses dados, desde a captura para comercialização entre grandes corporações transnacionais, até a facilidade com que esses dados são obtidos. $\mathrm{Na}$ verdade, a atual geração tecnológica de grandes corporações tem a violação e comercialização de dados pessoais como grandes elementos de catalização de tecnologia da informação e comunicação.

Ao tratar do tema de proteção de dados pessoais, é imprescindível ter em conta a experiência de uma sociedade cada vez mais movida por dados. No contexto da Internet das coisas, por exemplo, verifica-se a crescente conectividade com os mais diversos dispositivos de tecnologia, armazenando uma gama de informações acerca das atividades diárias dos usuários, quer dizer, atividades de caráter pessoal. Nesse ponto, deve ser destacado o fato de os dados pessoais dizerem

\footnotetext{
${ }^{9}$ Apesar das facilidades introduzidas com as tecnologias em rede, importa destacar que mesmo esses benefícios podem ser vistos com ressalva, se considerado que a desigualdade social também é impeditiva desse acesso.
} 
respeito ao caráter "privado" da vida do indivíduo, por isso o tema da proteção de dados e as informações geradas pela internet e pelos dispositivos tecnológicos merece especial atenção jurídica (MAGRANI, 2019, p. 97).

Nessa linha, os dispositivos tecnológicos utilizados no cotidiano das pessoas são equipados com sensores capazes de captar aspectos do mundo real, como a temperatura, umidade, presença, preferências e enviar a centrais que recebem essas informações e as utilizam de forma inteligente. É importante evidenciar que o contexto envolve um volume massivo de dados sendo processado diariamente, permitindo que seja possível conhecer cada vez mais indivíduos em seus hábitos, preferências, desejos e tentando, assim, direcionar suas escolhas. Tanto que, essa necessidade foi facilmente vista pelo mercado, que tem explorado a possibilidade de customização automática de conteúdo nas plataformas digitais, "inclusive capitalizando essa filtragem com publicidade direcionada por meio de rastreamento de cookies e processos de retargeting ou mídia programática" (MAGRANI, 2019, p. 35).

Sobre essa relação entre as preferências dos usuários e as publicidades e anúncios na Web, não é preciso se debruçar em pesquisas para encontrar usuários que se deparam diariamente com ofertas relacionadas a produtos que sequer tenham pesquisado. Com efeito, inúmeros usuários da rede poderiam relatar ter comentado sobre algum produto que, em seguida, apareceu nos anúncios das redes sociais.

Nessa perspectiva, embora a tecnologia traga inegáveis benefícios às pessoas, acaba criando problemas à proteção de privacidade, cada vez mais exposta, em decorrência da captação de dados pessoais pelos dispositivos vinculados à Internet. Nesse cenário, atualmente "a rede é a nova ideologia do capitalismo sem limites". Isso porque, a manipulação de dados, por meio de sensores em todos os lados, inseridos em casas totalmente inteligentes e automatizadas, relógios, roupas, automóveis, aparelhos que geram imagens, números, sentimentos é cada vez mais comum e escapa às estruturas estatais de controle. Pessoas emitem dados que, processados e extraídos, transformamse em informações que "valem dinheiro e poder" negociadas por poderes privados (LÔBO; BOLZAN DE MORAIS, 2019, p. 3).

Conforme assinalado anteriormente, por meio dos bancos de dados, milhares de informações podem ser sintetizadas e armazenadas. O que chama atenção, especialmente no decorrer dos últimos anos, é a forma como essas informações pessoais têm sido manipuladas, desde sua coleta, até seu armazenamento. Com os irrefreáveis avanços tecnológicos, aumenta-se a capacidade de comunicação dessas informações e também a variedade de formas de como elas podem utilizadas ou apropriadas, assim como a forma como podem influir no cotidiano das pessoas. Nesse sentido, com o aumento do número de sujeitos que podem ter acesso a informações pessoais 
cada vez mais detalhadas e precisas desses bancos de dados, existe uma preocupação acerca de como definir a própria autonomia dos usuários (DONEDA, 2011, p. 92-93).

Ao dissertar acerca da necessidade de proteção de dados pessoais, Rodotà afirma que estes são "expressão de liberdade e dignidade pessoais e, como tal, não se deve tolerar que um dado seja usado de modo a transformar um indivíduo em objeto sob vigilância constante”. Sob esse prisma, o autor confronta a realidade de esquadrinhamento a que as pessoas têm sido submetidas, por meio da vigilância por vídeo e tecnologias biométricas, transformando-se em "pessoas na rede" que, permanentemente nesta, aos poucos são configuradas para transmitir e receber sinais que permitam escanear e perfilar movimentos, hábitos e contatos, modificando o significado e o conteúdo da autonomia desses indivíduos (2008, p. 19).

O tratamento e violação de dados sensíveis, além da ampla utilização não consentida por terceiros de dados pessoais marcados pela capacidade de seu uso discriminatório tanto pelo Estado, quanto pelo mercado, pode ser verificado em inúmeros exemplos e, por isso, torna-se uma preocupação de âmbito global. A título ilustrativo, em 2017, no Canadá, uma empresa de produtos sexuais (Standard Inovation) passou a fornecer um vibrador que possuía um sistema diferenciado (conectava-se por rede ao bluetooth ou wi-fi do celular, por meio de um aplicativo) que permitia seu acesso remoto. O uso do aplicativo definia preferências dos usuários em relação ao ritmo e tipo da vibração e enviava dados (ritmo das vibrações, intensidade, tempo de uso, etc) para os servidores da empresa relacionados ao seu uso. No entanto, não havia nos termos de uso do produto ou do aplicativo a indicação da existência dessa coleta dados, nem um sistema de segurança das informações adequado (MULHOLLAND, 2018, p. 161-162). Essa realidade demonstra o quanto os usuários podem estar expostos e ter sua intimidade e privacidade facilmente violadas por diversos programas e plataformas da rede.

Além disso, Lôbo e Bolzan de Morais explicam que a "escalada da rede" afeta todos os estilos de vida, inclusive a política, transformando a democracia, na medida em que as redes sociais, a instantaneidade das informações e a supressão das fronteiras avançam. A comunicação em rede, conforme lição dos autores, além de despertar o senso de cooperação direto com os representantes políticos, também permitiu a manipulação invisível da eleição de Donald Trump nos Estados Unidos. Nesse caso, a empresa Cambridge Analytica usou dados pessoais de milhões de usuários do Facebook para criar um programa de software capaz de influenciar as escolhas dos eleitores, visando grupos específicos em sua publicidade e manipulando dados para, de fato, orientar o resultado da eleição $(2019$, p. 4$)$.

Pela multiplicidade de casos em que podem ser verificados o uso e manipulação dos dados pessoais, muito se tem discutido e analisado sobre possibilidades jurídicas de regulação da proteção 
dessas informações. No Brasil, por exemplo, a privacidade recebe proteção infraconstitucional pelo Código Civil, que protege a vida privada, e pelo Código de Defesa do Consumidor, que dedica uma seção à proteção de dados e cadastros de consumidores. Além disso, o Marco Civil da Internet, vigente desde 2014, traz alguns dispositivos destinados à proteção da privacidade, como é o caso do artigo $3^{\circ}$, que elenca tal proteção como princípio a ser observado na disciplina da Internet (MAGRANI, 2019, p. 62).

Ainda, recentemente a Lei Geral de Proteção de Dados Pessoais foi aprovada no país (LGPD - Lei n. 13.709/18) e, embora não esteja em vigor até o momento, dispõe sobre o tratamento desses dados pessoais, por meio físico ou digital, ao reconhecer a tutela dessas informações para a proteção de direitos, como a liberdade de expressão e comunicação, privacidade, honra e imagem. De acordo com as disposições da referida lei, dado pessoal é aquele composto por informações relacionadas à pessoa natural identificada ou identificável (artigo $\left.5^{\circ}, \mathrm{I}\right)$. Por outro lado, dado pessoal sensível se refere à "origem racial ou étnica, convicção religiosa, opinião política, filiação a sindicato ou a organização de caráter religioso, filosófico ou político, dado referente à saúde ou à vida sexual, dado genético ou biométrico, quando vinculado a uma pessoa natural" (artigo $5^{\circ}$, II) (BRASIL, 2018). Enfim, a LGPD possui inúmeros dispositivos destinados a regular a coleta, uso, tratamento e compartilhamento de dados.

Inobstante a existência de legislações que, de certa forma, procuram conferir maior proteção aos dados de usuários da rede e tecnologias, questiona-se se esses instrumentos legais são suficientes perante a atuação do mercado, de poderes privados e até mesmo do Estado em relação à manipulação dessas informações de caráter pessoal. Até porque, diante da pandemia Covid-19, há exemplos de países que estão utilizando de dados armazenados em redes de telefone, por exemplo, para verificar o controle do isolamento social.

No Brasil, em 17 de março de 2020, o governo publicou a Medida Provisória n. 954, determinando o compartilhamento de dados pelas empresas de telecomunicações com o Instituto Brasileiro de Geografia e Estatística, com o objetivo de dar suporte à produção de estatísticas oficiais durante a pandemia. A medida prevê que as empresas de telefonia devem liberar a relação de nomes, números de telefone e endereços dos consumidores, pessoas físicas ou jurídicas para o IBGE. Todavia, esse dispositivo foi questionado no Supremo Tribunal Federal, tanto que foi suspenso pelo plenário, em razão da possibilidade de causar danos irreparáveis à intimidade e ao sigilo da vida privada de mais de uma centena de milhão de usuários dos serviços de telefonia fixa e móvel ${ }^{10}$ (CONJUR, 2020).

\footnotetext{
${ }^{10}$ De acordo com a notícia divulgada pelo Conjur (2020): “O colegiado concordou com a ministra, no sentido de
} que a MP não define como e para que serão usados dados coletados. Além disso, não apresenta mecanismos 
Conforme restou demonstrado, há uma gama de exemplos em que é possível verificar a manipulação de dados pessoais seja para controle da pandemia, para vender produtos, para obter dados ou para manipular esses dados em favor de determinado objetivo. Resta compreender se as políticas nacionais dos Estados serão capazes de abarcar e controlar esses mecanismos, principalmente diante de situações de crises e diante da globalização e das novas tecnologias avançando em um ritmo muito mais rápido do que as vias institucionais dos Estados são aptas a enfrentar.

\section{CORRELAÇÕES ENTRE A UTILIZAÇÃO DOS DADOS PESSOAIS, A ATUAÇÃO DE PODERES PRIVADOS E OS PROCESSOS DEMOCRÁTICOS}

Com base nos argumentos dissertados nas páginas anteriores, o caminho percorrido pela pesquisa até o momento permite evidenciar a existência de algumas crises do Estado impulsionadas pela globalização, pelas novas tecnologias e pela crescente ascensão de poderes privados interferindo em domínios públicos. Desse modo, as conexões entre mercados, instituições, produtos, pessoas e a "rede" fizeram com que boa parte dos mecanismos de poder e controle do Estado se tornassem insuficientes, principalmente em razão da dependência da política em relação à economia, bem como pelo fato da tecnologia evoluir numa velocidade muito superior a que a engrenagem institucional estatal é capaz de alcançar.

Além desses fatores, necessário elucidar a maneira pela qual as questões que impactam o cotidiano das pessoas apresentam alguns contrapontos entre os avanços da tecnologia e o papel do Estado e, por via de consequência, do Direito, sempre colocando em dúvida sua atuação em relação a exercer ou não a disciplina dessas inovações. A velocidade com que a tecnologia digital e de dados tem avançado impõe desafios constantes às administrações públicas e, no caso da proteção de dados pessoais, não tem sido diferente, já que a captação e manipulação de dados na rede é uma prática cada vez mais comum.

Talvez um dos pontos que imprima maior dificuldade à regulação da manipulação de dados, por exemplo, possa ser elucidado pela própria maneira como o Estado foi estruturado durante a modernidade, colocando-o, hoje, em dificuldades para atender as demandas da atual sociedade globalizada. Isso porque, questões envolvendo a Internet ultrapassam fronteiras, ou seja, não conseguem ser resolvidas tão somente no âmbito nacional de um único Estado, bem como, em

técnicos para evitar vazamentos acidentais ou o uso indevido dos dados. Rosa Weber também apontou que a MP deveria demonstrar interesse público legítimo na troca dessas informações e que, ao editá-la, caberia ao Poder Executivo se atentar aos critérios de necessidade, adequação e proporcionalidade da medida”. 
inúmeras situações, as medidas tomadas pelos Estados são inefetivas diante da influência de poderes privados que operam em mais de um país.

Aliás, em uma reportagem de 2016, em edição internacional do New York Times, já se apontava a dominância da Google no cenário global. A matéria destacou que a Google Inc. atua como uma verdadeira instância decisória quando se trata de garantir a privacidade na rede. Desde o reconhecimento do direito ao esquecimento no cenário internacional e a fixação da responsabilidade da ferramenta de buscar na proteção de dados, a Google passou a analisar milhares de requerimentos para a supressão de resultados de buscas. No entanto, sem a mínima transparência, tem decidido pela permanência ou retirada desses resultados da Web (BAPTISTA; KELLER, 2016, p. 127). Ocorre que, a captura dos processos decisórios pelos atores econômicos é uma prática generalizada. Dessa forma, os governos passam por dificuldades no enfrentamento dessas resistências poderosas e articuladas de manipulação do poder.

Para avançar nessa etapa, o estudo pretende correlacionar a manipulação de dados pessoais por agentes privados com os processos democráticos dos países. Esse ponto da pesquisa é de especial relevância, já que a proteção de dados pessoais, enquanto cláusula geral de tutela da pessoa humana e do direito à privacidade é um requisito essencial da democracia. Nesse sentido, a capacidade de tratamento e manipulação de dados pessoais, ao ser impulsionada pelas tecnologias avançadas de inteligência artificial, gera grandes bases de dados levando a análises probabilísticas e resultados que, "ao mesmo tempo em que atingem os interesses de uma parcela específica da população, retiram a capacidade de autonomia do indivíduo e seu direito de acesso ao consumo de bens e serviços e a determinadas políticas públicas ${ }^{11}$ ”, bem como seu direito ao voto, pela perda de alternativas reais de escolha nas eleições (MUHLOLLAND, 2018, p. 173).

Ao passo em que as redes sociais se tornaram parte integral da vida pessoal das pessoas, assim como de sua atividade política e da atuação de seus representantes, os partidos e movimentos de representação social aproveitam o espaço para engajar eleitores, atacar opositores e pautar debates em torno de alguns interesses. Nessa linha, é comum observar "o uso orquestrado de redes de robôs (botnets) para gerar um movimento em determinado momento, manipulando treding topics e o debate em geral". Um estudo realizado pela Diretoria de Análise de Políticas Públicas da

\footnotetext{
11 "Um dos motivos para nosso sistema ter se tornado menos democrático — para ter se tornado menos eficaz em traduzir as opiniões do povo em políticas públicas, nos meus termos — é que muitos temas importantes foram removidos da contestação política nas últimas décadas. As legislaturas, diz o argumento, estão tolhidas em sua capacidade de exercer a vontade do povo devido ao poder crescente dos burocratas, ao papel preponderante desempenhado pelos bancos centrais, ao avanço do controle de constitucionalidade e à importância cada vez maior dos tratados e organizações internacionais. Mas há ainda uma peça importante nesse quebra-cabeça antidemocrático: mesmo em áreas nas quais os parlamentos conservam poder real, estão fazendo um mau trabalho em traduzir a visão da população em políticas públicas. Eleitos pelas pessoas para representar suas opiniões, os legisladores estão cada vez mais isolados da vontade popular” (MOUNK, 2019, p. 96).
} 
Fundação Getúlio Vargas identificou essas ações nas eleições americanas de 2010, na eleição de Donald Trump em 2016 e no plebiscito de saída do Reino Unido da União Europeia (Brexit). Segundo esse estudo, no Brasil, o cenário não é diferente, pois "ações orquestradas de robôs ocorreram em momentos-chave da política nacional, como a aprovação da Reforma Trabalhista, a greve geral de 2017, as eleições de 2014, o debate sobre o Impeachment e a eleição municipal de São Paulo em 2016" (RUEDIGER, 2018, p. 9).

Ainda, o impacto das novas tecnologias e dados pessoais, especificamente em relação ao uso do aplicativo de bate-papo Whats App nas últimas eleições presidenciais brasileiras, permite mais uma análise em relação aos processos democráticos. Com efeito, a intensa disseminação de notícias falsas e discursos de ódio sem limitações, codificadas por uma criptografia de ponta a ponta, além da manipulação de dados pessoais por grupos econômicos que procuram influenciar o resultado da eleição, evidenciam tamanha violação da privacidade dos usuários (LÔBO, BOLZAN DE MORAIS, 2019, p. 7-8). De fato, essas realidades demonstram como a manipulação de dados pode impactar diretamente a democracia dos países, aumentando as assimetrias de poderes e o distanciamento entre as elites e as classes vulneráveis da população.

Mais do que um processo de utilização de dados, a venda dessas informações entre empresas privadas é uma prática cada vez mais comum e que foge ao controle do Estado. Por exemplo, os casos de Trump e Brexit envolveram o manuseio de grandes volumes de informações depositadas pelos usuários da plataforma Facebook, enviados às empresas que as compraram, para fins de análise e mineração de dados, em colaboração com empresas eleitorais de comunicação e publicidade, que por sua vez, usavam a avaliação da personalidade do eleitor para guia-lo pelo algoritmo (LÔBO, BOLZAN DE MORAIS, 2019, p. 8).

Com a compra de dados pessoais dos consumidores, as empresas são capazes de elaborar perfis de consumo, o que pode incrementar a venda de produtos e serviços, além de aumentar seu controle sobre as pessoas, em relação a seus processos decisórios, seja na compra de um produto ou serviço ou na decisão de voto de uma eleição. De certa forma, a regulação de coleta e uso desses dados é contemplada, no Brasil, pela Lei Geral de Proteção de Dados (LGPD), a qual estabelece critérios de uso dos dados pessoais (MULHOLLAND, 2018, p. 175). Contudo, embora ainda não haja vigência desses dispositivos, questiona-se a capacidade de efetividade desse instrumento normativo, diante da atuação de empresas privadas atuando nesse "novo mercado".

À medida que as tecnologias digitais em rede deram uma nova dimensão à necessidade de proteção de algumas garantias e preceitos constitucionais, no Brasil, há uma Proposta de Emenda Constitucional (PEC) n. 19/2019, em tramitação no Congresso Nacional, por meio da qual se propõe alterar a Constituição Federal para incluir a proteção de dados pessoais entre os direitos e garantias 
fundamentais e para fixar a competência privativa da União para legislar sobre proteção e tratamento de dados pessoais (BRASIL, 2019).

Questiona-se, a partir dessa proposta, a (in)suficiência de um direito fundamental incluído na Constituição Federal quando, na verdade, se está diante de um elemento que não se prende a fronteiras e, portanto, não se vincula necessariamente à jurisdição de um Estado, como é o caso da Internet. De fato, conferir proteção fundamental no Brasil terá efeito sobre o Facebook, o Twitter, a Google? Daí decorre, essencialmente, a incapacidade do Estado para o controle das organizações privadas que o circulam e que atuam para além dele.

Não se trata de ignorar a relevância de um tratamento constitucional à matéria, mas compreender que, isoladamente, talvez não seja suficiente para causar um impacto real e efetivo sobre essas relações. Mesmo porque, numa interpretação sistemática, já poderia depreender-se a inconstitucionalidade e o caráter antidemocrático das práticas exemplificadas ao longo do trabalho, a partir de direitos e princípios já amplamente consagrados nas Constituições dos países envolvidos e que não obstam a interferência de poderes privados.

Além desses fatores, dada a característica de regulação privada que é inerente ao próprio funcionamento da Internet, os agentes do mercado têm ingerência sobre a tradução desses "direitos" na vida cotidiana das pessoas, por meio de diferentes ferramentas, como os filtros de busca e a própria disponibilização de serviços que permitem o acesso e armazenamento de informações privadas dos usuários.

Não é preciso tomar como ilustração apenas as empresas que atuam mundialmente. Recentemente, o jornal The Intercept Brasil denunciou a venda de dados de usuários da Vivo para diversas outras empresas no país. A reportagem evidencia, além de outras práticas, a contratação da divisão de dados pela administração do estádio Allianz Parque, em São Paulo, para comparar o perfil e o fluxo de turistas que assistiram à final da Copa do Brasil de 2015 ao público do show do músico David Gilmour, na semana seguinte ${ }^{12}$. Nesse caso, a grande questão jurídica envolvida diz respeito aos clientes, que não são informados sobre a comercialização de seus dados (THE INCERCEPT BRASIL, 2020).

Enfim, a forma como a manipulação desses dados impacta diretamente a democracia é que mais preocupa, já que em diversos casos os governos compram esses dados para subsidiar políticas públicas. Portanto, nos Estados Democráticos de Direito contemporâneos o problema que se põe é verdadeiramente delimitar de que modo intervir se as estruturas estatais existentes já não conseguem

\footnotetext{
${ }^{12}$ Segundo dados da reportagem, a Vivo consegue captar dados dos seus clientes por meio do aplicativo Smart Steps e os vende para diversas empresas, inclusive fora do Brasil, como é o caso da Pizza Hut, Shell, Starbucks e Samsung (THE INTERCEPT BRASIL, 2020).
} 
conter a atuação dos poderes privados, bem como as questões envolvendo a Internet ou a rede ultrapassam as fronteiras do Estado-nação.

Nesse ponto, Rodotà explica que a insistência sobre a necessidade de considerar esses problemas regulatórios de um ponto de vista "constitucional" e, por isso, nacional, indica com clareza o caminho que o Direito precisa percorrer para dar respostas adequadas à maneira pela qual as tecnologias estão dando nova forma às nossas sociedades. Na visão do autor, "não é pensável uma transferência do modelo da soberania nacional na dimensão global. Nem do ponto de vista realista nem teórico é possível levantar a hipótese de um mundo governado por um único centro, coisa já difícil nos Estados Nacionais" (2003, p. 10). Insistir numa perspectiva de "velhas" instituições estatais para respostas a problemas sem fronteiras é praticamente negar a realidade.

Sobre as imbricações entre as crises do Estado, explica Ferrajoli que é precisamente a crise econômica, gerada pela desregulação financeira, o principal fator moderno de crise, fazendo com que o papel normativo do direito estatal seja esvaziado pela perda de soberania dos Estados, "pela crise de representatividade dos partidos, pelo conflito de interesses e pela sobreposição, aos poderes públicos, dos poderes econômicos e financeiros de caráter transnacional" (2015, p. 147-148). De todo modo, esse diagnóstico de crises do Estado tem estreita correlação com a forma como a tecnologia avança, por meio da globalização e da atuação de poderes privados. Da ausência de controle em relação à manipulação de dados pessoais decorre mais uma demonstração dessas crises, pela carência de suas instituições suficientemente aptas a interagir perante a atuação dos poderes privados.

\section{CONCLUSÃO}

A abordagem teórica realizada no decorrer da pesquisa permite evidenciar a forma como a globalização e os avanços tecnológicos afetam o Estado e o colocam em situações de crises. Além disso, esse cenário demonstra o quanto as questões de uma sociedade global ultrapassam as fronteiras e os marcos regulatórios de um único Estado-nação. Nessa perspectiva e, considerando a interferência de poderes privados, os problemas decorrentes da utilização, venda e armazenamento de dados dos usuários da Web têm relação direta com os processos democráticos dos países.

Isso porque, conforme abordagem do estudo, há uma série de poderes privados atuando fora do controle dos Estados, indicando o enfraquecimento da capacidade decisória dos Estados, bem como da própria democracia. Manipulação de eleições, interferência em políticas públicas, compra de dados pessoais e ingerência sobre as decisões de consumo da população são práticas comuns e 
que ameaçam os processos democráticos dos países, os quais têm por pressuposto o respeito a uma série de direitos, liberdades e princípios que são atropelados pela dinâmica em que operam os poderes privados, sobretudo em um cenário globalizado permeado por relações completamente desamarradas de componentes territoriais.

Ao final, a hipótese de pesquisa foi confirmada, tendo em vista que, além dos argumentos corroborados acima, entende-se que a inclusão da proteção de dados pessoais no catálogo de direitos fundamentais brasileiro, considerando esse cenário de crises do Estado e de protagonismo de poderes privados, reveste-se de algumas dificuldades práticas que ainda precisam ser enfrentadas. Pensar as questões da tecnologia (regulação, controle) deve levar em conta seu caráter transfronteiriço, pois não há como contemplar, no âmbito da jurisdição de um único Estado, situações que ultrapassam fronteiras e tratam da sociedade globalizada, do fluxo de informações, da interdependência e do poder econômico.

\section{REFERÊNCIAS}

BAPTISTA, Patrícia; KELLER, Clara Iglesias. Por que, quando e como regular as novas tecnologias? Os desafios trazidos pelas inovações disruptivas. Revista de Direito Administrativo, Rio de Janeiro, v. 273, p. 123-163, set. 2016. ISSN 2238-5177. Disponível em: <http://bibliotecadigital.fgv.br/ojs/index.php/rda/article/view/66659>. Acesso em: 18 mai. 2020.

BECK, Ulrich. O que é globalização? Equívocos do globalismo: respostas à globalização. Tradução de André Carone. São Paulo: Paz e Terra, 1999.

BOBBIO, Norberto; MATTEUCCI, Nicola; PASQUINO, Gianfranco. Dicionário de Política. 11. ed. Brasília: Universidade de Brasília, 1998.

BOLZAN DE MORAIS, Jose Luis. As crises do Estado e da Constituição e a transformação espaço-temporal dos direitos humanos. 2 ed. Porto Alegre: Livraria do Advogado, 2011.

BOLZAN DE MORAIS, Jose Luis. O fim da geografia institucional do Estado. A "crise" do Estado de Direito. In: BOLZAN DE MORAIS, Jose Luis (org). Estado e Constituição: o "fim" do Estado de Direito. Florianópolis: Tirant Lo Blanch, 2018. p. 17-38.

CHEVALLIER, Jacques. O Estado pós-moderno. Tradução de Marçal Justen Filho. Belo Horizonte: Fórum, 2009.

CHIGNOLA, Sandro. A vida, o trabalho, a linguagem. Biopolítica e Biocapitalismo. Tradução de Sandra Dall Onder. Cadernos IHUideias, ano 13, n. 228, vol. 13, 2015. 
CONJUR. STF barra MP que previa compartilhamento de dados pessoais com IBGE, 2020. Disponível em: < https://www.conjur.com.br/2020-mai-07/stf-barra-mp-previa-compartilhamentodados-pessoais-ibge>. Acesso em: 20 mai. 2020.

DONEDA, Danilo. A proteção dos dados pessoais como um direito fundamental. Espaço Jurídico. Joaçaba, v. 12, n. 2, p. 91-108, jul./dez. 2011. Disponível em: < https://portalperiodicos.unoesc.edu.br/espacojuridico/article/view/1315>. Acesso em: 18 mai. 2020.

FARIA, José Eduardo. O direito na economia globalizada. São Paulo: Malheiros, 2004.

FERRAJOLI, Luigi. A Democracia através dos Direitos: o constitucionalismo garantista como modelo téorico e como projeto político. São Paulo: Revista dos Tribunais, 2015.

GERVASONI, Tássia A. Estado e Direito em trânsito na pós-modernidade. Florianópolis: Empório do Direito, 2017.

JULIOS-CAMPUZANO, Alfonso de. La globalización ilustrada. Ciudadanía, derechos humanos y constitucionalismo. Madrid: Dykinson, 2003.

LÔBO, Edilene; BOLZAN DE MORAIS, José Luiz. New technologies and the current communications model in the 2018 brazilian elections. Novos Estudos Jurídicos, v. 24, n. 3, p. 1056-1087, 2019. Disponível em: <https://siaiap32.univali.br/seer/index.php /nej/article/view/15532>. Acesso em: 07 mai. 2020.

MAGRANI, Eduardo. Entre dados e robôs: ética e privacidade na era da hiperconectividade. Porto Alegre: Arquipélago Editorial, 2019.

MOUNK, Yascha. O povo contra a democracia. Por que nossa liberdade corre perigo e como salvá-la. Tradução de Cássio de Arantes Leite e Débora Landsberg. São Paulo: Companhia das Letras, 2019.

MULHOLLAND, Caitlin Sampaio. Dados pessoais sensíveis e a tutela de direitos fundamentais: uma análise à luz da lei geral de proteção de dados (Lei 13.709/18). Revista de Direitos e Garantias Fundamentais, Vitória, v. 19, n. 3, p. 159-180, set./dez. 2018. Disponível em: < http://dx.doi.org/10.18759/rdgf.v19i3.1603>. Acesso em: 20 mai. 2020.

RODOTÀ, Stefano. A vida na sociedade da vigilância: a privacidade hoje. Rio de Janeiro: Renovar, 2008.

RODOTÀ, Stefano. Palestra. Tradução de Myriam de Filippis. Rio de Janeiro, 2003. Disponível em: <www.rio.rj.gov.br/dlstatic/10112/151613/DLFE-4314.pdf/GlobalizacaoeoDireito.pdf>. Acesso em: 07 mai. 2020.

RUEDIGER, Marco Aurélio. Robôs, redes sociais e política no Brasil: estudo sobre interferências ilegítimas no debate público na web, riscos à democracia e processo eleitoral de 2018. Rio de Janeiro: Fundação Getúlio Vargas, 2017.

SASSEN, Saskia. Perdiendo el control? La soberania en la era de la globalización. Traducción de Víctor Pozanco. Barcelona: Belaterra, 2001. 
SASSEN, Saskia. Territorio, autoridad y derechos. De los ensamblajes medievales a los ensamblajes globales. Tradução de María Victoria Rodil. Buenos Aires: Katz, 2010.

SØRENSEN, Georg. La transformación del Estado - Más allá del mito del repliegue. Traducción de Ramón Cotarelo. Valencia: Tirant to Blanch, 2010.

THE INTERCEPT BRASIL. Vigiar e lucrar. Disponível em: < https://theintercept.com/ 2020/04/13/vivo-venda-localizacao-anonima/>. Acesso em: 20 mai. 2020.

Trabalho recebido em 10 de junho de 2020

Aceito em 11 de setembro de 2021 